\title{
Unusual Anatomy of a Second Maxillary Molar - a Rare four- Root Configuration Case Report
}

\author{
Dr. Thiago de Almeida Prado Naves Carneiro,DDS, MSc \\ PhD student, Department of Occlusion, Fixed Prostheses, and Dental Materials, School of Dentistry, \\ Universidade Federal de Uberlândia, Uberlândia, Minas Gerais Brazil. \\ tapncarneiro@hotmail.com

\begin{abstract}
Although it is a very rare situation, four-rooted maxillary second molars can occur. The existence of two palatal roots is extremely rare and ranges about only 0.4\%. The aim of this study is to present and document a very rare anatomic configuration of a four-rooted maxillary second molar. Anatomic variation in the number of roots and root canals can occur in any tooth, although some cases can be extremely rare as the one presented here.Clinicians should be aware of this possibility before considering any kind of treatment.
\end{abstract}

Keywords: Molar, Dental Anatomy, Anatomical Variation

\section{INTRODUCTION}

Usually the maxillary second molars are described in the literature as a teeth that have 3 roots with 3 or 4 root canals. Understanding of the presence of additional roots and unusual root canals is essential and determines the success of endodontic treatment ${ }^{1}$.

The existence of maxillary second molars with 4 roots ( 2 buccal and 2 palatal) is extremely rare and ranges about only $0.4 \%$.This information comes from a study that showed, after the examination of two different horizontally angled radiographs of 1,000 maxillary second molars, just four with four roots ${ }^{2}$. They also examined two hundred cases of second molars with endodontic treatment and found only one with four roots. Although this situation is extremely rare, the unusual root and canal anatomy associated to maxillary molars has been presented in some studies ${ }^{2-9}$.

The aim of this study is to present and document a very rare anatomic configuration of an upper fourrooted second molar.

\section{CASe Report}

A 34 year old man presented to the Urgency Dental Care section at the Clinical Hospital of the Federal University of Uberlândia - Brazil. The patient had a volumetric augmentation of the left side of the face and was claiming of pain and pulsing sensation. At the intraoral examination, the patient presented poor oral hygiene and the maxillary left second molar crow was completely destructed by caries. In the radiographic exam, the tooth presented no possibilities of treatment due to the severe destruction of the most part of it (Figure 1).

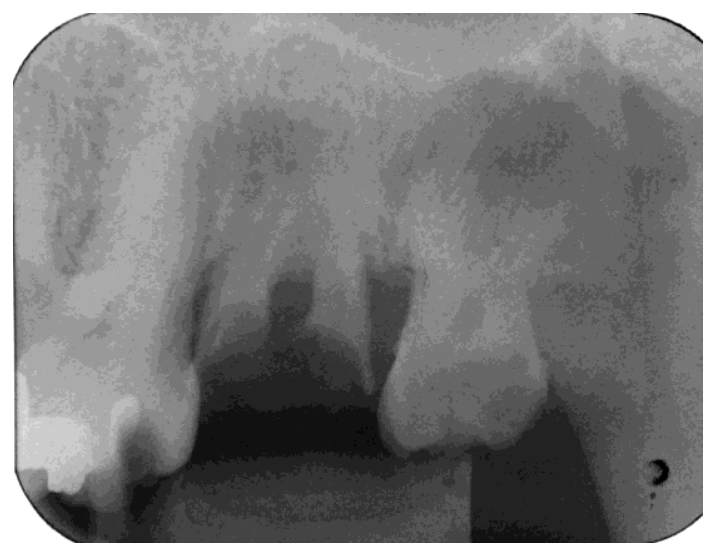

Figure1. Periapical Radiograph 
No abnormality was noted in the radiographic image besides the massive destruction of the crow due to bacterial activity. There was no choice besides the tooth extraction. The patient presented no contraindications for the surgery and was immediately medicated and prepared for the extraction surgery. The surgery was performed under local anesthesia with lidocaine $20 \mathrm{mg} / \mathrm{ml}+$ adrenaline 12.5 $\mu \mathrm{g} / \mathrm{ml}$. The tooth presented some difficulty to be extracted and when it was finally removed, a big surprise came with it. A four rooted maxillary second molar (Figure 2). The suture was performed, the prescription was done and the patient was oriented about the post operatory precautions.

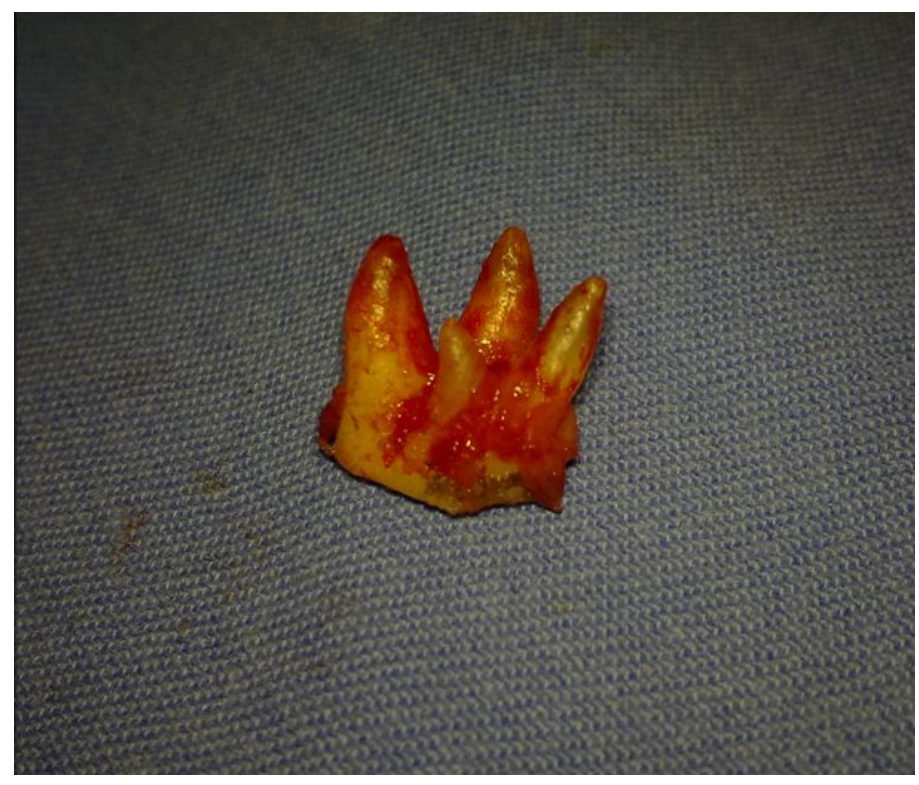

Figure2. Maxillarysecond molar with 4 roots

\section{DisCuSSION}

Although it is a very rare situation, four-rooted second molars exists. A classification of 4-rooted maxillary molar was described,dividing this variation into 3 types, according to root separation level and divergence of the roots angles ${ }^{8}$. Type I have two widely divergent, long, and tortuous palatal roots. The buccal roots are often less divergent. Type II has four separate roots, but the roots are often shorter, parallel, and have buccal and palatal root morphology with blunt root apices. In the type III, the distobuccal root appears to stand alone and may even diverge to the distobuccal. Based on this classification, the maxillary left second molar presented in this clinical report could be classified as Type II.

The diagnosis of extra canals with a normal number of roots may be difficult and dangerous because of their superposition and their usual small size. In these situations, most of the extra root canals may be left untreated during endodontic procedures due to the difficulty to identify extra canals on the radiographic examination. In this way,an more accurate image examination as a CBCT scan must be performed when the presence of extra roots is a possibility. Thorough theknowledge of anatomical variations and different types of anomalies in the maxillofacial region, multipleradiographs with different angles or cone-beam computedtomography (CBCT) could be helpful. The major advantage of the CBCT over the conventional radiograph is the possibilityof three-dimensional image examination and also the obtaining of multiple slices of tooth roots and their canals. This image exam is able to add precious information to the diagnosis when dealing with uncommon anatomical variations ${ }^{10}$.

In the present case, the massive destruction of the crown contraindicated the endodontic therapy and the tooth was extracted. Although the incidence of maxillary molars with four roots is rare, they do occur and the clinicians should be aware of this fact and prepared to face this situation.

\section{Conclusion}

Anatomic variation in the number of roots and root canals can occur in any tooth. Although some cases can be extremely rare as presented in this case report.Clinicians should be aware of this possibilitywhen considering endodontic treatment. Examination of several radiographs taken from different angles and and CT scans should be considered before any decision of treatment planning. 


\section{REFERENCES}

[1] Peters OA. Current challenges and concepts in the preparation of root canal systems: a review. J Endod. 2004 Aug; 30(8):559-67.

[2] Libfeld H, Rotstein I. Incidence of four-rooted maxillary second molars: literature review and radiographic survey of 1,200 teeth. J Endod. 1989 Mar; 15(3):129-31.

[3] Malagnino V, Gallottini L, Passariello P. Some unusual clinical cases on root anatomy of permanent maxillary molars. J Endod. 1997 Feb; 23(2):127-8.

[4] Stone LH, Stroner WF. Maxillary molars demonstrating more than one palatal root canal. Oral Surg Oral Med Oral Pathol. 1981 Jun; 51(6):649-52.

[5] Badole GP, Bahadure RN, Warhadpande MM, Kubde R. A rare root canal configuration of maxillary second molar: a case report. Case Rep Dent. 2012; 2012:767582.

[6] Ingle J. I., Backland L. K., Peters D. D., Buchanan S., and Mullaney T.P., "Preparation of coronal and radicular spaces," in Endodontics, J. I. Ingle and L. K. Backland, Eds., pp. 877-991, Williams \&Wilkins, 6th edition, 2008.

[7] Weine F. S, "Access cavity preparation and initiating treatment," in Endodontic Therapy, F. S. Weine, Ed., pp. 266-278, Mosby, St. Louis, Mo, USA, 5th edition, 1989.

[8] Christie WH, Peikoff MD, Fogel HM. Maxillary molars with two palatal roots: a retrospective clinical study. J Endod. 1991 Feb; 17(2):80-4.

[9] Di Fiore PM. A four-rooted quadrangular maxillary molar. J Endod. 1999 Oct;25(10):695-7.

[10] Patel S, Dawood A, Whaites E, Pitt Ford T. New dimensions in endodontic imaging: Part 1. Conventional and alternative radiographic systems. IntEndod J 2009; 42:447-62. 